\title{
Design and Analysis of Adaptive Sliding Mode with Exponential Reaching Law Control for Double-Fed Induction Generator Based Wind Turbine
}

\author{
Kheira Belgacem ${ }^{1}$, Abdelkader Mezouar ${ }^{2}$, Najib Essounbouli ${ }^{3}$ \\ ${ }^{1,2}$ Electrical Engineering, Taher Moulay University, Algeria \\ ${ }^{3}$ CReSTIC Laboratory, Reims University, 10026 Troyes CEDEX, France
}

\begin{tabular}{l}
\hline Article Info \\
\hline Article history: \\
Received Jun 30, 2018 \\
Revised Aug 26, 2018 \\
Accepted Sep 14, 2018 \\
\hline Keyword: \\
Doubly fed induction generator \\
Variable speed wind turbine \\
Power control \\
Sliding mode control (SMC) \\
Sliding mode control (SMC) \\
with exponential reaching law \\
(ERL)
\end{tabular}

\begin{abstract}
The main objective of this paper is to continue the development of activities of basic and applied research related to wind energy and to develop methods of optimal control to improve the performance and production of electrical energy from wind. A new control technique of Double fed induction generator for wind turbine is undertaken through a robust approach tagged nonlinear sliding mode control (SMC) with exponential reaching law control (ERL). The SMC with ERL proves to be capable of reducing the system chattering phenomenon as well as accelerating the approaching process. A nonlinear case numerical simulation test is employed to verify the superior performance of the ERL method over traditional power rate reaching strategy. Results obtained in Matlab/Simulink environment show that the SMC with ERL is more robust, prove excellent performance for the control unit by improving power quality and stability of wind turbine.
\end{abstract}

\section{Corresponding Author:}

Kheira Belgacem,

Laboratory of Electrical Engineering,

Taher Moulay University,

(20 000) Saida, Algeria.

Email: kheira.belgacem@yahoo.fr

\section{INTRODUCTION}

Wind energy is a free, renewable resource, so no matter how much is used today, there will still be the same supply in the future. Wind energy is also a source of clean, non-polluting, electricity. Unlike conventional power plants, wind plants emit no air pollutants or greenhouse gases [1].

The latest generation wind turbines operate at variable speed. This type of operation makes it possible to increase the energy efficiency, to lower the mechanical loads and to improve the quality of the electrical energy produced.

A Doubly Fed Induction Generator (DFIG) is an electrical asynchronous three-phase machine with open rotor windings which can be fed by external voltages. The typical connection scheme of this machine is reported in Figure 1. The stator windings are directly connected to the line grid, while the rotor windings are controlled by means of an inverter [2]. This solution is very attractive for all the applications where limited speed variations around the synchronous velocity are present, since the power handled by the converter at rotor side will be a small fraction (depending on the slip) of the overall system power. In particular, for electric energy generation applications, it is important to note that the asynchronous nature of the DFIG allows producing constant frequency electric power with a variable mechanical speed, in addition reduced copper losses and wider operational range are obtained with respect to standard squirrel-cage induction machine [3]. 


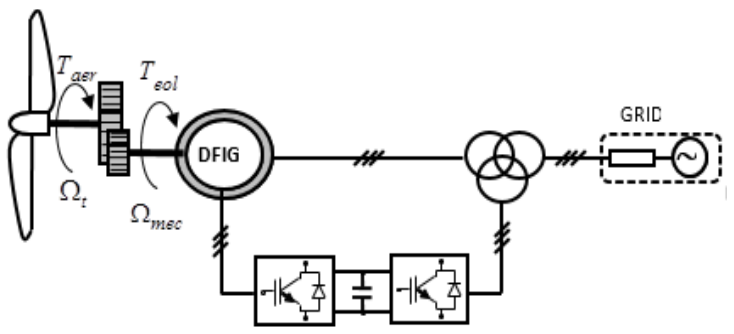

Figure 1. The typical connection scheme of DFIG

The sliding mode control (SMC) approach has heretofore been used for many dynamic control systems due to its simplicity of implementation and their robustness against both plant uncertainties and external disturbances, suitable transient performance and quick response.

The SMC has gain considerable concerns in the application of DFIG control. In [4], a dynamical sliding mode power control scheme is proposed for DFIG. In [5], the SMC method is employed to control the rotational speed in the rotor side as well as the dc-link voltage in the grid side of a wind energy conversion system; a model predictive control based SMC is proposed to control a three-phase grid-connected converter and the grid current total harmonic distortion and the switching losses are largely mitigated in [6].

One major bug of using SMC in practical applications is the chattering. Chattering causes several damages to the mechanical components. Different methods were proposed to minimize chattering such as by replacing the sign function with saturation [7] or using Quasi-SMC and fuzzy mathematics [8]. In [9] a optimized sliding mode control (SMC) strategy to maximize existence region for single-phase dynamic voltage restorers. It is shown analytically that there exists an optimum sliding coefficient which enlarges the existence region of the sliding mode to its maximum. Also, it is pointed out that the optimum sliding coefficient improves the dynamic response. In [10] the author proposes a SMC control strategy which combines a switched policy with a time-based adaptation of the control gain, thereby allowing to effectively deal with a very conservative prior knowledge of the upper bounds on the uncertainties, that usually leads to a large control authority, and related performance degradation. In [11] this paper proposes two model-free sliding mode control system structures. The new structures are compared with a model-free intelligent proportional-integral (PI) control system structure. The design and implementation of adaptive Second Order Sliding Mode Control for a four wheels Skid-Steered Mobile Robot [12].

The combination of a sliding mode control algorithm and fuzzy logic developing for robot manipulator's trajectory [13]. This paper aims to propose a SMC control scheme based on a novel exponential reaching law (ERL), the objective of this paper is the control of active and reactive powers in the variable speed wind turbine. The nonlinear sliding mode control with an exponential reaching law is used to achieve our objective. In [4] we has used the conventional sliding-mode control to control the power produced by a wind turbine, but in this paper, we will use the same method but by employing an exponential reaching law (ERL) proposed by Fallaha et al. to calculate the control law [14].

The advantage of the proposed approach is that allows to obtain a good reference tracking and the suppression of chatter phenomenon. This paper is organized as follows. Firstly, In Section 2, the SMC conventional and SMC with ERL methods were be introduced. In Section 3, the ERL based SMC will be utilized in the control of DFIG for wind turbine generator. In Section 4, simulation will be conducted and the performance of the proposed method will be tested with the simulation results. In Section 6, the conclusion of the entire paper will be provided.

\section{THE CONTROL SCHEME}

In this section, first we represent the theoretical structure of the simple sliding mode and also the exponential sliding mode control for the general dynamics of rigid systems.

\subsection{Sliding Mode Control (SMC)}

The SMC was widely used in the literature. This success is due to its simplicity of implementation and to its robustness towards the parameter variations and the external disturbances. It is to be switched with the discontinuous functions of the dynamic system the structure so that the state vector to follow a trajectory $S(X)=0$ in the state space. 


\subsubsection{Choice of switching surface}

The surface of sliding is a scalar function such as the error on the variable to adjust glide to this surface and aims towards the origin of the plan of phase. So, the surface represents the wished dynamic behavior. We find in the literature of various forms of the surface, among which each gives better performances for certain uses. J. Slotine proposes a shape of general equation to determine the surface of sliding which insures the convergence of a variable towards its wished value, [5]:

$$
S(X)=\left(\frac{\partial}{\partial t}+\lambda_{x}\right)^{r-1} e(X)
$$

where:

$r$ is the relative degree of the sliding surface.

$e(x)$ is the erreur

$\lambda_{x}$ is a constant.Concerning the development of the control law.

The parameters of the sliding surface will be chosen so that the error trajectories will start from the initial point to the sliding surface and continue to slide near the sliding surface. The first stage is called the reaching stage and the second stage is called the sliding stage. In the sliding stage, the error trajectories will follow the following Lyapunov condition,

$$
V(X)=\frac{1}{2} S^{2}(X)
$$

Its derivative given by:

$$
\dot{V}(X)=S(X) \dot{S}(X)
$$

\subsubsection{Convergence condition}

One must decrease of the Lyapunov function to zero. For this purpose, it is sufficient to assure that is derivative negative. So:

$$
S(X) \dot{S}(X)<-\eta|S(X)| \text { for } \forall X \neq 0
$$

where $\eta$ is a strictly positive constant. Satisfying above condition keeps the system trajectories remaining on the sliding surface.

One need to note that the $S$ involved in equation (4) is different from the $S$ stated in equation (1). The $S$ in equation (4) stands for the reaching law while the $S$ in equation (1) represents the sliding surface. Apparently, it can be seen from equation (4) that $\dot{S}$ and its derivative $S$ have different signs with each other, and that is the mean cause of the chattering phenomenon. Suppose $S$ is positive at the starting point, then its derivative is negative, which makes $S$ approaches the sliding surface where the value of $\dot{S}$ is equal to 0 ; when $S$ reaches the sliding surface for the first time, it will continue to decrease until its value becomes negative and its derivative becomes positive, hence, the trajectory will increase subsequently until it becomes positive again and similar process repeats again. That is the cause of the chattering phenomenon.

Two parts have to be distinguished in the control design procedure. The first one concern the attractivity of the state trajectory to the sliding surface and the second represents the dynamic response of the representative point in sliding mode. This latter is very important in terms of application of non-linear control techniques, because it eliminates the uncertain effect of the model and external perturbation. Among the literature, one can chose for the controller the following expression:

$$
u=u_{e q}+u_{n}
$$

where: $u_{e q}$ the control function is defined by Utkin and noted equivalent control, for which the trajectory response remains on the sliding surface [15]. $u_{n}$ is the discrete control which is determined to verify the convergence condition. 


$$
u_{n}=K \operatorname{sign}(S(X))
$$

Two major problems exist within the study of SMC theory: the chattering phenomenon and the approaching speed, which largely impact the application of SMC. The appearance of the chattering phenomenon near the sliding manifold is inevitable as long as the high speed switching law is utilized. Thus, the appearance of chattering phenomenon restricts its domain of application due to the fact it may excite some undesirable high frequency dynamics which further causes severe damages to the system. Literature [16] proposes a kind of ERL based SMC technique which can reduce the chattering phenomenon to a certain extent. In order to further accelerate the reaching speed from the initial point to the sliding manifold, a novel SMC method based on ERL will be proposed in this section.

\subsection{Sliding Mode Control with Exponential Reaching Law}

With the aid of a new approach of choosing $K$ we can control the tracking error as well as preventing the chattering occurrence. We can select $K$ by an exponential procedure [17].

$$
\dot{S}=\frac{K|S|^{\alpha}}{N(S)} \operatorname{sign}(S)
$$

where

$$
N(S)=\beta+(1-\beta) e^{-\gamma|S|^{\mu}}
$$

$\alpha, \beta, \gamma$ and $\mu$ are all positive numbers, $|S|$ denotes the absolute value of $S$, and $0<\alpha, \beta<1$

It is evident that equation (7) has faster reaching speed than that of SMC since an exponential term exists in equation (7). Apart from that, when $|S|$ grows larger, the coefficient of the reaching law approaches $\frac{K}{N(S)}$ which is larger than $\frac{K}{\beta}$, hence, the reaching speed is faster. Meanwhile, when the trajectory reaches near the sliding manifold and $|S|$ reaches 0 , then the chattering phenomenon is reduced due to the existence of the exponential term and the increase of $N(s)$.

\section{DFIG WIND TURBINE APPLICATION}

\subsection{Modeling of the wind turbine and gearbox}

Consider a wind turbine provided with blades of length $R$ resulting in a generator through a multiplier of speed of gain $G$

The aerodynamic power appearing at the level of the rotor of the turbine. It is given by [18]:

$$
P_{t}=\frac{1}{2} C_{p}(\lambda) \cdot \rho \cdot \pi \cdot R^{2} V^{3}
$$

where $\rho$ is the air density, $R$ is the blade length and $V$ is the wind velocity. Knowing the speed of the turbine, the aerodynamic torque is this directly determined by:

$$
T_{a e r}=\frac{P_{t}}{\Omega_{t}}
$$

The multiplier of speed, which is arranged between the wind turbine and the generator, aims at adapting the speed of the turbine, rather slow, to the one that requires the generator. It is modelled by following tows equations

$$
\left\{\begin{array}{l}
T_{g}=\frac{T_{a e r}}{G} \\
\Omega_{t}=\frac{\Omega_{m e c}}{G}
\end{array}\right.
$$


where $T_{g}$ is the driving torque of the generator and $\Omega_{m e c}$ is the generator shaft speed.

The power coefficient represents the aerodynamic efficiency on the wind turbine. It depends on the characteristic of the turbine [19],[20]. The ratio of speed is defined as the report between the linear speed of blades and the wind speed:

$$
\lambda=\frac{\Omega_{t} \cdot R}{V}
$$

A typical relationship between $C_{p}$ and $\lambda$ is shown in Figure 2. It is clear from this figure that there is a value of $\lambda$ for which $C_{p}$ is maximum and that maximizes the power for a given wind speed. The peak power for each wind speed occurs at the point where $C_{p}$ is maximized [20],[21].

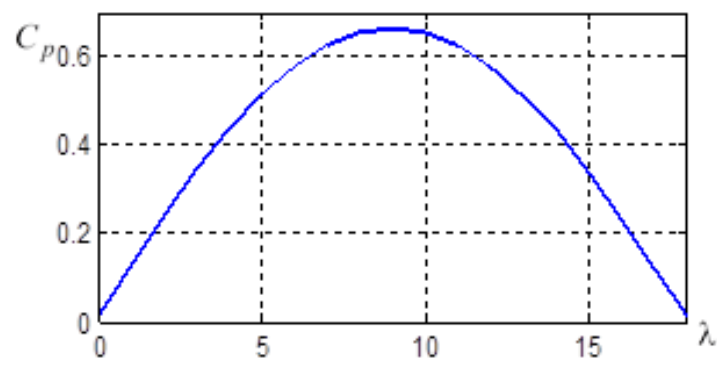

Figure 2. Power coefficient for the wind turbine model

\subsection{Modeling of the Double Fed Induction Generator}

The model of state of Park of the generator under the following matrix shape [21]:

$$
\left\{\begin{array}{l}
v_{s d}=R_{s} i_{s d}+\frac{d}{d t} \phi_{s d}-\omega_{s} \phi_{s q} \\
v_{s q}=R_{s} i_{s q}+\frac{d}{d t} \phi_{s q}+\omega_{s} \phi_{s d} \\
v_{r d}=R_{r} i_{r d}+\frac{d}{d t} \phi_{r d}-\omega_{r} \phi_{s q} \\
v_{r q}=R_{r} i_{r q}+\frac{d}{d t} \phi_{r q}+\omega_{r} \phi_{r d}
\end{array}\right.
$$

where $R_{s}$ and $R_{r}$ are the stator and rotor phase resistances, respectively. $\omega_{s}=\omega+\omega_{r}$, and $\omega=p \cdot \Omega_{m e c}$ is the electrical speed where $p$ is the pair pole number. The stator and rotor flux can be expressed as

$$
\begin{gathered}
\left\{\begin{array}{l}
\phi_{s d}=L_{s} i_{s d}+M i_{r d} \\
\phi_{s q}=L_{s} i_{s q}+M i_{r q}
\end{array}\right. \\
\left\{\begin{array}{l}
\phi_{r d}=L_{r} i_{r d}+M i_{s d} \\
\phi_{r d}=L_{r} i_{r q}+M i_{s q}
\end{array}\right.
\end{gathered}
$$

where $i_{s d}, i_{s q}, i_{r d}$ and $i_{r q}$ are the direct and quadrature stator and rotor currents, respectively. The active and reactive powers exchanged with the electrical network also depend on electric variables of the stator and on the rotor. In the stator, the active and reactive powers are respectively given by [21]: 


$$
\left\{\begin{array}{l}
P_{s}=v_{s d} i_{s d}+v_{s q} i_{s q} \\
Q_{s}=v_{s q} i_{s d}-v_{s d} i_{s q}
\end{array}\right.
$$

The electromagnetic torque is expressed as

$$
T_{e m}=p\left(\phi_{s d} i_{s q}-\phi_{s q} i_{s d}\right)
$$

\section{CONTROL STARTEGY OF THE DOUBLE FED INDUCTION GENERATOR}

\subsection{Decoupling of the active and reactive powers}

The principle of orientation of flux statorique consists in aligning the statorique flux according to the axis " $d$ " by the rotating reference table. This last constraint is favorable to have a simplified model of command. By setting the quadrate component of the stator to the null value as follows:

$$
\phi_{s}=\phi_{s d} \Rightarrow \phi_{s q}=0
$$

Equation (6) is simplified as indicated below:

$$
\left\{\begin{array}{c}
\phi_{s d}=L_{s} i_{s d}+M i_{r d} \\
0=L_{s} i_{s q}+M i_{r q}
\end{array}\right.
$$

By neglecting the stator resistance $R_{S}$

$$
\left\{\begin{array}{l}
v_{s d}=0 \\
v_{s q}=V_{s}
\end{array}\right.
$$

Using equations (12), (13), (14) and (17) the stator active and reactive power can then be expressed only versus these rotor currents as:

$$
\left\{\begin{array}{l}
P_{s}=V_{s} i_{s q}=-V_{s} \frac{M}{L_{s}} i_{r q} \\
Q_{s}=V_{s} i_{s d}=\frac{V_{s} \phi_{s}}{L_{s}}-\frac{V_{s} M}{L_{s}} i_{r d}
\end{array}\right.
$$

\subsection{SMC Regulator Synthesis}

The Figure 3 represents the plan of the simulation. The machine is directly connected to the network of the side statorique. Of an other, the circuit rotorique is fed through a converter to MLI. The errors between the reference powers and those measured at the level of the stator are handled by the algorithm of considered control, to design the reference tensions of the rotor. These reference tensions as well as those in the entrance of the converter to MLI are used by the technique of modulation considered for the synthesis of the signals of order for the bidirectional switches of the converter.

In this section, we develop a law command to control the stator active and reactive power. Choosing the following switching functions:

$$
\left\{\begin{array}{c}
S_{P_{S}}=\left(P_{s}^{*}-P_{s}\right)+\lambda_{P} \int\left(P_{s}^{*}-P_{s}\right) d t \\
S_{Q_{S}}=\left(Q_{s}^{*}-Q_{s}\right)+\lambda_{Q} \int\left(Q_{s}^{*}-Q_{s}\right) d t
\end{array}\right.
$$

where $P_{s}^{*}, Q_{s}^{*}$ denote the reference stator active and reactive power, respectively; $\lambda_{P}, \lambda_{Q}$ are the coefficients of the switching function. The derivatives of both switching functions are: 


$$
\left\{\begin{array}{c}
\dot{S}_{P_{s}}=-\dot{P}_{s}+\lambda_{P}\left(P_{s}^{*}-P_{s}\right) \\
\dot{S}_{Q_{S}}=-\dot{Q}_{s}+\lambda_{Q}\left(Q_{s}^{*}-Q_{s}\right)
\end{array}\right.
$$

Based on equation (21), we have:

$$
\left\{\begin{array}{l}
\dot{S}_{P_{s}}=V_{s} \frac{M}{L_{s}}\left(\dot{i}_{r q}+\lambda_{P} i_{r q}\right)+\lambda_{P} P_{s}^{*} \\
\dot{S}_{Q_{s}}=V_{s} \frac{M}{L_{s}}\left(\dot{i}_{r d}+\lambda_{Q} i_{r d}-\lambda_{Q} \frac{\phi_{s}}{M}\right)+\lambda_{Q} Q_{s}^{*}
\end{array}\right.
$$

Considering equation (13)-(14) and (15), we have

$$
\left\{\begin{array}{l}
i_{r d}=\frac{1}{\sigma_{r}}\left(v_{r d}-R_{r} i_{r d}+\sigma_{r} \omega_{r} i_{r q}\right) \\
i_{r q}=\frac{1}{\sigma_{r}}\left(v_{r q}-R_{r} i_{r q}-\sigma_{r} \omega_{r} i_{r d}-V_{s} \frac{g M}{L_{s}}\right)
\end{array}\right.
$$

where $\sigma=1-\frac{M^{2}}{L_{s} L_{r}}$ is the scatter coefficient of the magnetic flows. Substituting equation (25) into equation (24), we have

$$
\dot{S}=\left[\begin{array}{l}
G_{1} \\
G_{2}
\end{array}\right]+\left[\begin{array}{ll}
f_{1} & f_{11}
\end{array}\right]\left[\begin{array}{l}
v_{r d} \\
v_{r q}
\end{array}\right]
$$

where

$$
\begin{aligned}
& \dot{S}=\left[\begin{array}{l}
\dot{S}_{P_{S}} \\
\dot{S}_{Q_{S}}
\end{array}\right] \\
& f_{1}=\frac{V_{s} M}{\sigma L_{s} L_{r}} \\
& G_{1}=f_{2} i_{r d}+f_{3} i_{r q}+f_{4} \\
& f_{2}=-V_{s} \frac{M R_{r}}{\sigma L_{s} L_{r}} \\
& f_{3}=\frac{V_{s} M}{L_{s}}\left(\omega_{r}+\lambda_{P}\right) \\
& f_{4}=\lambda_{P} P_{s}^{*} \\
& f_{11}=\frac{V_{s} M}{\sigma L_{s} L_{r}} \\
& G_{2}=f_{22} i_{r d}+f_{33} i_{r q}+f_{44} \\
& f_{22}=\frac{M V_{s}}{L_{s}}\left(\omega_{r}+\lambda_{Q}\right)
\end{aligned}
$$




$$
\begin{aligned}
& f_{33}=-V_{s} \frac{R_{r} M}{\sigma L_{s} L_{r}} \\
& f_{44}=-V_{s} \frac{g M^{2}}{\sigma L_{s}^{2} L_{r}}+\lambda_{Q} Q_{s}^{*}
\end{aligned}
$$

Now we substitute the reaching law in equation (7) into equation (26), which yields

$$
\begin{aligned}
& v_{r d}=\frac{1}{f_{1}}\left(\left[\frac{K|S|^{\alpha}}{\beta+(1-\beta) e^{-\gamma|S|^{\mu}}} \operatorname{sign}\left(S_{Q_{S}}\right)\right]-f_{2} i_{r d}-f_{3} i_{r q}-f_{4}\right) \\
& v_{r q}=\frac{1}{f_{11}}\left(\left[\frac{K|S|^{\alpha}}{\beta+(1-\beta) e^{-\gamma|S|^{\mu}}} \operatorname{sign}\left(S_{P_{S}}\right)\right]-f_{22} i_{r d}-f_{33} i_{r q}-f_{44}\right)
\end{aligned}
$$

Figure 3 shows the block diagram of the system implemented with the sliding mode control (SMC) with exponential reaching law control (ERL).

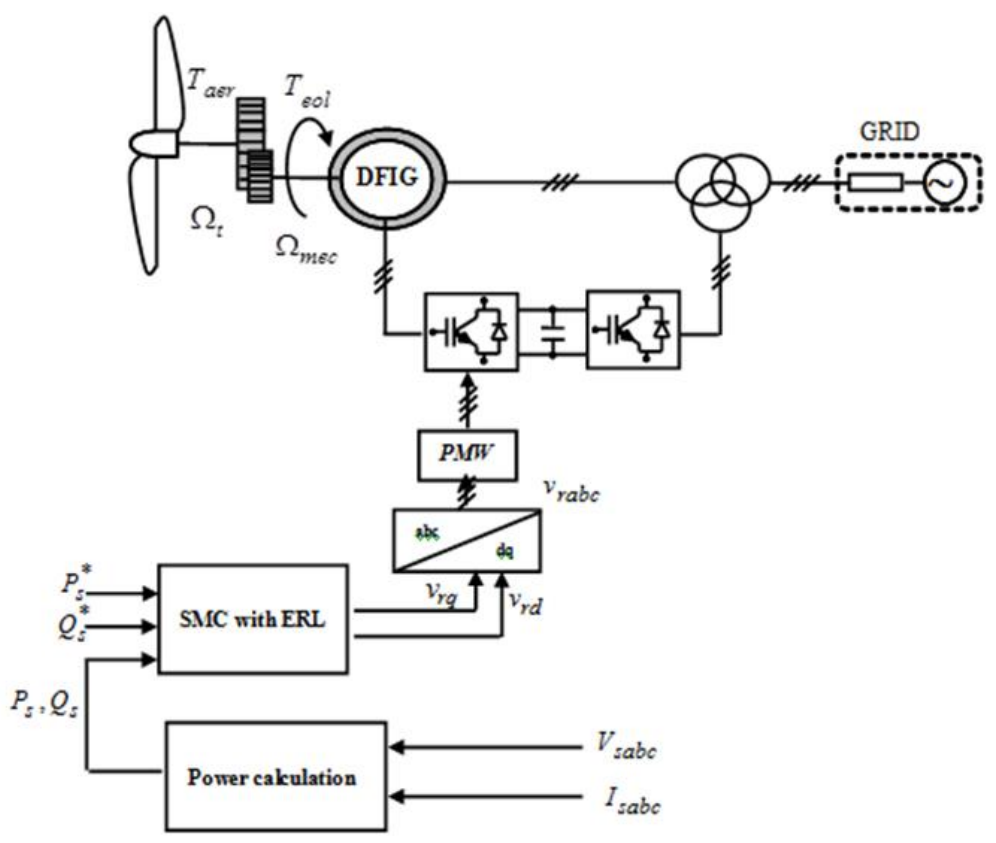

Figure 3. Configuration of the power control of the DFIG with SMC with ERL

\section{RESULTATS AND DISCUSSION}

To test the performance of the proposed ERL based SMC in wind turbine active/reactive power regulation; a comparative study is conducted under variable wind speed scenarios. A 7.5 KW DFIG wind turbine, simulation model is constructed in Matlab/Simulink. The parameters utilized are listed in Table 1.

Table 1. DFIG nominal parameters

\begin{tabular}{ccc}
\hline $7.5 \mathrm{KW}$ & $380 / 660 \mathrm{~V}$ & $50 \mathrm{~Hz}$ \\
\hline $\mathrm{P}=2$ & $\mathrm{Rs}=0.455 \mathrm{Ohm}$ & $\mathrm{Rr}=0.62 \mathrm{Ohm}$ \\
$\mathrm{M}=0.078 \mathrm{H}$ & $\mathrm{Ls}=0.084 \mathrm{H}$ & $\mathrm{Lr}=0.081 \mathrm{H}$ \\
\hline
\end{tabular}

Table 2. Turbine parameters

\begin{tabular}{c}
\hline Diameter $=13$ \\
\hline Gearbox $=35$ \\
Number of blades $=3$ \\
\hline
\end{tabular}

Table 3. (DFIG+TURBINE) parameters $\mathrm{J}=0.3125 \mathrm{kgm} 2$ $\mathrm{f}=0.00673 \mathrm{Kg} . \mathrm{m}$ 
In this section, we have chosen to compare the performances of the DFIG with two different controllers. The Sliding Mode Control will be first tested and will be the reference compared to the other: Sliding Mode Control with exponential reaching law control (ERL).

Figures 4 and 5 show the simulations results of the two methods in electromagnetic torque control, active and reactive power tracking and current statorique and rotorique. What needs to be noted is that the parameters utilized in the programming of the SMC that the $\lambda_{P_{S}}$ and $\lambda_{Q_{S}}$ are both chosen to be 25 and $\beta$ is fixed to be 0.5 , and $\alpha$ is 1 and the coefficients of the new switching function in equation (22) are both chosen to be 5 . The solvers are still Runge-Kutta (ode45) and the sampling rate is $25 \mu$ s. As it can be figured out from Figures 4 and 5 that the performance of the proposed ERL based SMC is better than that of the classical SMC in tracking the electromagnetic torque, Active and reactive power. Furthermore, the chattering phenomenon is largely reduced. It is evident that the curve of the ERL based SMC tracks the reference value precisely with little chatters. When utilizing the conventional SMC approache, high frequency chatters with high amplitude exist. These chatters are caused by the discontinuous switching function of the control input.

When the ERL based SMC approach is utilized, the discontinuous components of the control input have relatively higher gains, making the chatters more distinctive. The discontinuous component of the control input automatically decreases to an acceptable level and the sliding stage becomes much more smooth and precise.
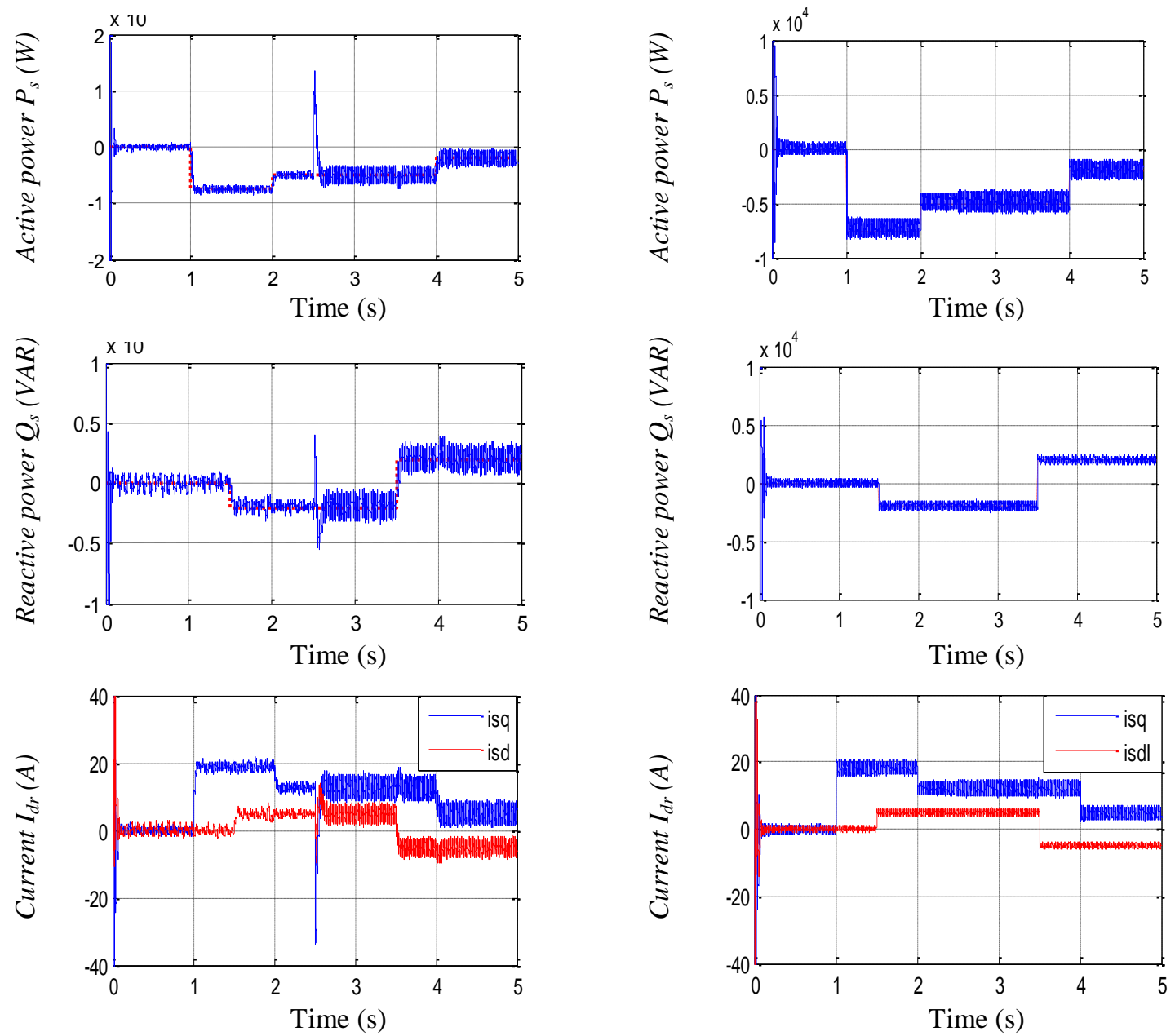


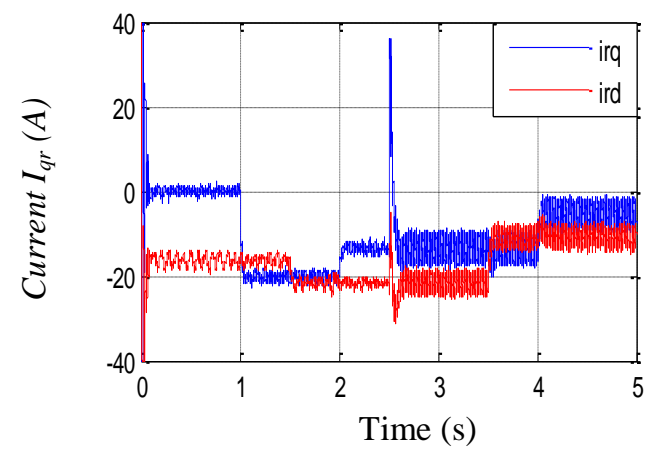

Figure. 4 power control of the DFIG with

\section{CONCLUSION}

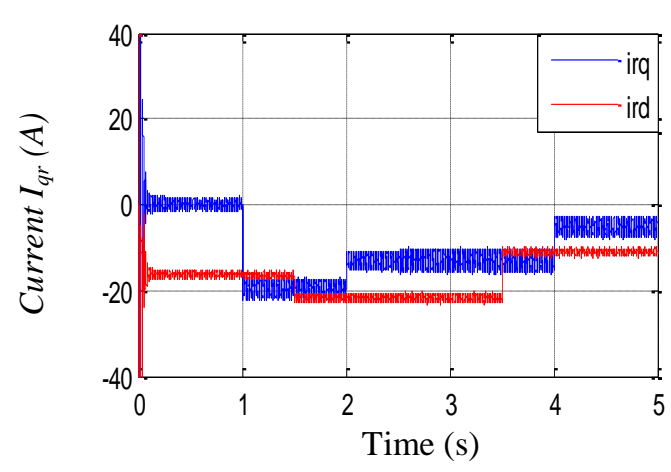

Figure. 5 power control of the DFIG with F -HOSTSM

In this paper, we have presented a complete system to produce electrical energy with a doubly-fed induction generator by the way of a wind turbine.

Once the complete model of the wind chain is validated, we spent optimizing active and reactive power injected to the grid. In this context, two robust control strategies have been studied and compared to show the improvement of the quality of energy and energy efficiency, particularly under the influence of the variation of wind parameters of the wind turbine.

The control of the machine has been presented in order to regulate the active and reactive powers exchanged between the machine and the grid. We proposes a DFIG wind turbine control technique with a novel sliding mode control technique under variable wind speed based on novel exponential reaching law (ERL). The proposed SMC is supposed to reduce the level of chattering phenomenon and accelerate the reaching process, which has been verified by the numerical simulation of a nonlinear controlled system.

\section{REFERENCES}

[1] A. Rosa, "Fundamentals of Renewable Energy Processes," Academic Press, Boston, MA, USA, 2012.

[2] K. Belgacem, "Fuzzy Logic Control of Double-Fed Induction Generator Wind Turbine," International Review of modelling and simulation (IREMOS), vol/issue: 6(01), 2013.

[3] N. Watanakul, "An Application of Wind Turbine Generator on Hybrid Power Conditioner to Improve Power Quality,” International Review of Electrical Engineering, vol/issue: 7(5), pp. 5487-5495, 2012.

[4] K. Belgacem, "Sliding Mode Control of a Doubly-fed Induction Generator for Wind Energy Conversion," International Journal of Energy Engineering, vol/issue: 30(01), pp 30-36, 2013.

[5] O. Boughazi, "Sliding Mode Backstepping Control of Induction Motor," International Journal of Power Electronics and Drive System (IJPEDS), vol/issue: 4(4), pp. 481-488, 2014.

[6] Merabet A., et al., "Implementation of sliding mode control system for generator and grid sides control of wind energy conversion system," IEEE Trans Sustain Energy, vol/issue: 7(3), pp. 1327-35, 2016.

[7] Liao K., et al., "A sliding mode based damping control of DFIG for interarea power oscillations," IEEE Trans Sustain Energy, vol/issue: 8(1), pp. 258-67, 2017.

[8] H. Aschemann and D. Schindele, "Sliding-mode control of a highspeed linear axis driven by pneumatic muscle actuators," IEEE Trans. On Industrial Electronics, vol/issue: 55(11), pp. 3855-3864, 2008.

[9] B. Belkacem, "Hybrid Fuzzy Sliding Mode Control of a DFIG Integrated into the Network," International Journal of Power Electronics and Drive System (IJPEDS), vol/issue: 3(4), pp. 351-364, 2013.

[10] S. Biricik, "Optimized Sliding mode control to maximize existence region for single-phase dynamic voltage restorers," IEEE Transactions on Industrial Informatics, vol/issue: 12(4), pp. 1486-1497, 2016.

[11] A. Pisano, "Switched/time-based adaptation for second-order sliding mode control," Automatica, vol. 64, pp. 126$132,2016$.

[12] R. Emil, "Model-free sliding mode control of nonlinear systems," Algorithms and experiments, Information Sciences, vol. 381, pp. 176-192, 2017.

[13] I. Matraji and A. Al-Durra, "Trajectory tracking control of skid-steered mobile robot based on adaptive second order sliding mode control," Control Engineering Practice, vol. 72, pp. 167-176, 2018.

[14] Moussaoui, et al., "Fuzzy Adaptive Sliding-Mode Control Scheme for Uncertain Underactuated Systems," Advances and Applications in Nonlinear Control Systems. Springer International Publishing, pp. 351-367, 2016.

[15] Fallaha C. J., et al., "Sliding-mode robot control with exponential reaching law," IEEE Trans Ind Electron, vol/issue: 58(2), pp. 600-10, 2011.

[16] M. H. Rahman, et al., "Control of an exoskeleton robot arm with sliding mode exponential reaching law force," Intelligent Robots and Systems (IROS), 2010 IEEE/RSJ International Conference on. IEEE, 2010.

[17] T. K. A. Brekken and N. Mohan, "Control of a doubly fed induction wind generator under unbalanced grid voltage conditions," IEEE Transaction on Energy Conversion, vol. 22, pp. 129-135, 2007. 
[18] Poitiers F., et al., "Advanced control of a doubly-fed induction generator for wind energy conversion," Electric Power Systems Research, vol/issue: 79(7), pp. 1085-1096, 2009.

[19] Aouzellag D., et al., "Modelling of doubly fed induction generator with variable speed wind for network power flow control," JTEA'06, Tunis, 2006.

[20] J. M. Rodriguez, "Incidence on power system dynamics of high penetration of fixed speed and doubly fed wind energy systems: Study of the Spanish case," IEEE Trans. Power Syst., vol. 17, pp. 1089-1095, 2002.

[21] T. Ghennam, et al., "A vector hysteresis current control applied on three-level inverter. Application to the active and reactive power control of doubly fed induction generator based wind turbine," International Review of Electrical Engineering, vol/issue: 2(2), pp. 250-259, 2007.

\section{BIOGRAPHIES OF AUTHORS}
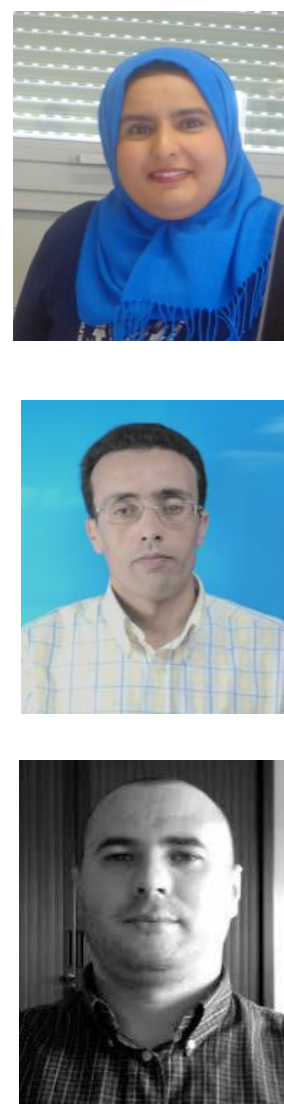

Kheira BELGACEM received B.S. degree in Electrical Engineering from Taher Moulay University, Saida, Algeria, in 2001 and the M.S. degree from High National Schools of Technical Studies (ENSET) in 2009. Subsequently, she received the Ph.D. degree from Djillali Liabes University, Sidi Bel Abbès, Algeria, in 2014. She is currently a member of the Laboratory of Electrical Engineering, Taher Moulay University, Saida, Algeria. His research interests include electrical machines and drives, sliding mode control, modelling and control of wind turbines, and renewable energy.

Abdelkader MEZOUAR was born in Mascara, Algeria, in 1974. He received the B.S. and M.S. degrees in Electrical Engineering from National Polytechnic School, Algiers, Algeria, in 1997 and 1999 respectively. Subsequently, he received the Ph.D. degree and the university habilitation from Djillali Liabes University, Sidi Bel Abbès, Algeria, in 2006 and 2008 respectively. He is currently the president of the Laboratory of Electrical Engineering, Taher Moulay University, Saida, Algeria. His research interests include electrical machines and drives, sliding mode control, observer techniques and renewable energy.

Najib Essounbouli received his bachelor degree in electrical from the University of Sciences and Technology of Marrakech (FSTG) Morocco, and DEA. and Ph. D. degrees both in electrical engineering from Reims University of Champagne Ardennes, in 2000 and 2004 respectively. From 2005 to 2010, he was an assistant professor with University Institute of Troyes, Reims Champagne Ardennes University. Since 2010, he has been a professor with the same institute. His research interests include fuzzy logic control, robust adaptive control, renewable energy and control drive. E-mail: najib.essounbouli@univ-reims.fr 